\begin{tabular}{|c|l|}
\hline Title & Mechanistic study of the selective hydrogenation of carboxylic acid derivatives over supported rhenium catalysts \\
\hline Author(s) & $\begin{array}{l}\text { Takashi, Toyao; Kan Wei, Ting; S. M. A. Hakim, Siddiki; Touchy, A beda S.; Onodera, W ataru; Maeno, Zen; A riga } \\
\text { Miwa, Hiroko; Kanda, Yasuharu; A sakura, Kiyotaka; Shimizu, Ken-ichi }\end{array}$ \\
\hline Citation & $\begin{array}{l}\text { Catalysis Science \& Technology, 9(19), 5413-5424 } \\
\text { https://doi.org/10.1039/c9cy01404g }\end{array}$ \\
\hline Issue Date & 2019-10-07 \\
\hline Doc URL & http://hdl.handle.net/2115/79489 \\
\hline Type & article(author version) \\
\hline File Information & Main text_Re_CST_HUSCAP.pdf \\
\hline
\end{tabular}

Instructions for use 


\section{Mechanistic study of the selective hydrogenation of carboxylic acid derivatives over supported rhenium catalysts}

Takashi Toyao, ${ }^{\text {aa,b }}$ Kah Wei Ting, ${ }^{a}$ S. M. A. Hakim Siddiki, ${ }^{a}$ Abeda. S. Touchy, ${ }^{a}$ Wataru Onodera, ${ }^{a}$ Zen Maeno, ${ }^{a}$ Hiroko Ariga-Miwa, ${ }^{a}$ Yasuharu Kanda, ${ }^{c}$ Kiyotaka Asakura, ${ }^{a}$ Ken-ichi Shimizu*a,b

a Institute for Catalysis, Hokkaido University, N-21, W-10, Sapporo 001-0021, Japan

${ }^{\mathrm{b}}$ Elements Strategy Initiative for Catalysts and Batteries, Kyoto University, Katsura, Kyoto 6158520, Japan

${ }^{\mathrm{c}}$ Applied Chemistry Research Unit, College of Environmental Technology, Graduate School of Engineering, Muroran Institute of Technology, 27-1 Mizumoto, Muroran 050-8585, Japan

${ }^{*}$ Corresponding authors

Takashi Toyao, Ken-ichi Shimizu

E-mail: toyao@cat.hokudai.ac.jp, kshimizu@cat.hokudai.ac.jp, TEL: +81-11-706-9164

†Electronic Supplementary Information (ESI) available: See DOI: 10.1039/x0xx00000x. 


\section{Abstract}

The structure and performance of $\mathrm{TiO}_{2}$-supported $\mathrm{Re}\left(\mathrm{Re} / \mathrm{TiO}_{2}\right)$ catalysts for selective hydrogenation of carboxylic acid derivatives have been investigated. $\mathrm{Re} / \mathrm{TiO}_{2}$ promotes selective hydrogenation reactions of carboxylic acids and esters that form the corresponding alcohols, and of amides that generate the corresponding amines. These processes are not accompanied by reduction of aromatic moieties. A Re loading amount of $5 \mathrm{wt} \%$ and a catalyst pretreatment with $\mathrm{H}_{2}$ at $500{ }^{\circ} \mathrm{C}$ were identified as being optimal to obtain the highest catalytic activity for the hydrogenation processes. The results of studies using various characterization methods, including X-ray diffraction (XRD), X-ray absorption fine structure (XAFS), X-ray photoelectron spectroscopy (XPS), and scanning transmission electron microscopy (STEM), indicate that the Re species responsible for the catalytic hydrogenation processes have sub-nanometer to a few nanometer sizes and average oxidation states higher than 0 and below +4 . The presence of either a carboxylic acid and/or its corresponding alcohol is critical for preventing the $\mathrm{Re} / \mathrm{TiO}_{2}$ catalyst from promoting production of dearomatized byproducts. Namely, although $\mathrm{Re} / \mathrm{TiO}_{2}$ is intrinsically capable of hydrogenating aromatic rings, carboxylic acids, alcohols, amides, and amines strongly adsorb on the Re species, which leads to suppression of this process. Moreover, the developed catalytic system was applied to selective hydrogenation of triglycerides that form the corresponding alcohols. 


\section{Introduction}

Hydrogenation reactions of carboxylic acids, esters, and amides are receiving increased attention because of their use in a variety of applications in the pharmaceutical and fine-chemical industry, as well as for upgrading bio-based chemical feedstocks. ${ }^{1-5}$ Although significant progress has been made in recent years, the development of catalysts that promote these processes remains a formidable task. The difficulties are predominantly a consequence of the fact that carboxylic acid derivatives are kinetically unreactive and thermodynamically stable as a result of the low electrophilicity of the carbonyl carbons. ${ }^{6}$ Although stoichiometric amounts of strong reducing agents are typically and effectively used to accomplish these reactions, use of these agents has serious drawbacks in terms of reagent/functional group compatibility, poor atom economy and safety especially when the processes are performed on an industrial scale. ${ }^{7}$ Alternative approaches that utilize catalytic reduction with $\mathrm{H}_{2}$ are undoubtedly more attractive because they are considerably more atom economic, environmentally benign and cost-effective. Therefore, substantial effort has been made for the development of these hydrogenation reactions, and some are industrially viable. ${ }^{7}$ However, because carboxylic acid derivatives are the most difficult substrates to hydrogenate, harsh reaction conditions are usually required. ${ }^{8}$ For instance, successful operation of a conventional Cu-Cr-based catalytic system for these hydrogenations requires the use of highly severe conditions $\left(T=250{ }^{\circ} \mathrm{C}, p_{\mathrm{H} 2}>20 \mathrm{MPa}\right)$ and high active metal loadings (ca. $20 \mathrm{wt} \%$ ). ${ }^{9}$ Moreover, these processes often are unselective and inefficient as a consequence of over-reduction. In particular, most catalytic systems are limited because they preferentially promote hydrogenation of aromatic systems over carboxylic acid groups. ${ }^{10-14}$ Because aromatic systems are present in many organic substances, this problem seriously limits the use of those hydrogenation processes in synthetic organic chemistry.

Catalysts comprised of platinum-group-metal complexes have played a leading role in carrying out selective hydrogenations. ${ }^{15-28}$ However, the chemical and thermal stabilities of these catalysts are typically poor, and separation of catalysts from products is relatively difficult. Another drawback of these homogeneous catalysts is that they often require the use of stoichiometric quantities of additives. As a result, the design and development of highly versatile heterogeneous catalysts for selective hydrogenation of carboxylic acids and their derivatives are highly desirable goals in organic chemistry. 
In this context, we have recently reported that $\mathrm{TiO}_{2}$-supported $\mathrm{Re}\left(\mathrm{Re} / \mathrm{TiO}_{2}\right)$ is a heterogeneous catalyst that, in the absence of additives, promotes selective hydrogenation reactions of various carboxylic acid derivatives that contain aromatic moieties. ${ }^{29,30}$ In the processes, carboxylic acids and esters are converted to corresponding alcohols, while amides are transformed to the corresponding amines. Importantly, this heterogeneous catalytic system does not promote hydrogenation of aromatic groups but preferentially hydrogenate carboxylic acid derivative groups. In addition to these simple hydrogenation processes, this catalyst can be employed in $\mathrm{N}$-alkylation reactions of amines, which proceed via the conversion of carboxylic acid (or esters) to the corresponding alcohols followed by reaction of the amine with the generated alcohol. Furthermore, low temperature $\left(T=150{ }^{\circ} \mathrm{C}\right)$ hydrogenation of $\mathrm{CO}_{2}$ to methanol ${ }^{31}$ and the $\mathrm{N}$-methylation reactions of amines, using $\mathrm{CO}_{2}$ and $\mathrm{H}_{2}$ as a methylation reagent, can be promoted using $\mathrm{Re} / \mathrm{TiO}_{2}$.

Although the earlier studies led to the development of a highly active and selective catalyst for hydrogenation of carboxylic acid derivatives, they did not reveal the precise nature of the catalytically active Re species. Moreover, little is known about the nature of the active species in a number of valuable Re promoted transformation ${ }^{32-42}$ despite having been the subject of scientific investigations for years. ${ }^{43-55}$ The main reasons for this are that Re often is highly dispersed on supports and is difficult to be reduced, and it can exist in a variety of oxidation states. ${ }^{56-65}$ This deficiency makes it highly desirable to carry out a comprehensive study of supported Re catalysts that focuses on gaining insight into a fundamental understanding of the catalytically active Re species.

In this study, we describe the results of a detailed mechanistic study of selective hydrogenation reactions of carboxylic acids and their derivatives catalyzed by $\mathrm{Re} / \mathrm{TiO}_{2}$. Important information was gained in this investigation using scanning transmission electron microscopy (STEM) and in situ methods such as X-ray diffraction (XRD), X-ray absorption fine structure (XAFS), and X-ray photoelectron spectroscopy (XPS). The results show that for effective hydrogenation processes the Re species in the catalyst should have sub-nanometer to a few nanometer sizes and an average oxidation state that is higher than 0 and below +4 . Furthermore, the co-presence of either the carboxylic acid derivatives and/or the corresponding products is important for preservation of the high selectivity of these catalytic reactions so that byproducts arising from reduction of aromatic moieties are not formed. The results of this 
investigation have not only provided mechanistic insight into $\mathrm{Re} / \mathrm{TiO}_{2}$-promoted hydrogenations, they also led to a better understanding of the behavior of Re on the solid surfaces, which are known to be interesting catalytically active systems. 


\section{Experimental}

\section{Materials and preparation of the catalysts}

Chemicals were obtained from commercial suppliers and used as received. $\mathrm{TiO}_{2}$ (ST-01, 188 $\left.\mathrm{m}^{2} \mathrm{~g}^{-1}\right)$ was purchased from Ishihara Sangyo Co., Ltd. $\mathrm{Al}_{2} \mathrm{O}_{3}\left(124 \mathrm{~m}^{2} \mathrm{~g}^{-1}\right)$ was prepared by calcination of $\mathrm{y}-\mathrm{AlOOH}$ (Catapal B) obtained from Sasol for $3 \mathrm{~h}$ at $T=900^{\circ} \mathrm{C}$. SiO 2 (Q-10, 300 $\left.\mathrm{m}^{2} \mathrm{~g}^{-1}\right)$ was purchased from Fuji Silysia Chemical Ltd. The carbon support $\left(296 \mathrm{~m}^{2} \mathrm{~g}^{-1}\right)$ was supplied by Kishida Chemical.

Precursors of $\mathrm{Re}(5) / \mathrm{TiO}_{2}\left(\mathrm{Re}=5 \mathrm{wt} \%\right.$ ) and $\mathrm{Re}(5) /$ Support (Support $=\mathrm{Al}_{2} \mathrm{O}_{3}, \mathrm{SiO}_{2}$, and Carbon) were prepared by mixing the corresponding support materials with appropriate metal sources, i.e., aqueous solution of $\mathrm{NH}_{4} \mathrm{ReO}_{4}$. In a typical preparation of $\operatorname{Re}(5) / \mathrm{TiO}_{2}, \mathrm{NH}_{4} \mathrm{ReO}_{4}$ $(0.72 \mathrm{~g})$ was added to a round-shaped glass vessel $(500 \mathrm{~mL})$ that contain $100 \mathrm{~mL}$ of deionized water. After sonication for $1 \mathrm{~min}, \mathrm{TiO}_{2}(9.5 \mathrm{~g})$ was added and the resulting solution was stirred at $200 \mathrm{rpm}$ for $15 \mathrm{~min}$ at r.t. The reaction mixture was then evaporated at $50^{\circ} \mathrm{C}$, and the residue was dried at $90{ }^{\circ} \mathrm{C}$ in air for $12 \mathrm{~h}$. The obtained material was calcined at $500^{\circ} \mathrm{C}$ in air for $3 \mathrm{~h}$. Prior to each experiment, the catalyst was prepared by reducing those precursors in a glass tube ( $T=500^{\circ} \mathrm{C}, t=0.5 \mathrm{~h}$ ) under a flow of $\mathrm{H}_{2}$. Other catalysts were also prepared in the same manner.

\section{Characterization of the catalysts}

STEM images were recorded on a JEM-ARM200F microscope (JEOL). The Cs-corrector CESCOR (CEOS GmbH, Germany) was used.

In situ XRD (Rigaku Ultima IV) measurements were conducted using a CuKa radiation source. Samples were heated under a flow of $5 \% \mathrm{H}_{2} / \mathrm{N}_{2}\left(30 \mathrm{~mL} \mathrm{~min}^{-1}\right)$ at temperatures up to $500{ }^{\circ} \mathrm{C}$ with a heating rate of $10{ }^{\circ} \mathrm{C} / \mathrm{min}$. XRD patterns were recorded under a flow of $5 \% \mathrm{H}_{2} / \mathrm{N}_{2}$ $\left(30 \mathrm{~mL} \mathrm{~min}^{-1}\right)$ at temperatures between r.t.-500 ${ }^{\circ} \mathrm{C}$. Ex situ XRD was performed by using a CuKa radiation source with a Rigaku Miniflex. Temperature programmed reduction by $\mathrm{H}_{2}\left(\mathrm{H}_{2}\right.$-TPR) was performed by using BELCAT II (MicrotracBEL).

Ti K-edge and Re L3-edge XAFS measurements were performed at the BL01B1 line (SPring8) using a $\mathrm{Si}(111)$ double crystal monochromator (proposal No. 2018B1126). For in situ analysis, samples in pellet form $(\varphi 10 \mathrm{~mm})$ were introduced into a quartz cell equipped with Kapton film windows and gas lines. Samples were heated under a flow of $5 \% \mathrm{H}_{2} / \mathrm{He}\left(100 \mathrm{~mL} \mathrm{~min}^{-1}\right)$ at 
temperatures up to $700^{\circ} \mathrm{C}$ with a heating rate of $10{ }^{\circ} \mathrm{C} / \mathrm{min}$. Spectra were recorded under a flow of $5 \% \mathrm{H}_{2} / \mathrm{He}\left(100 \mathrm{~mL} \mathrm{~min}^{-1}\right)$ at temperatures between $100-700{ }^{\circ} \mathrm{C}$. A measurements on $\mathrm{Re}$ metallic powder as a reference was made using a sample that is sealed in a glove bag filled with $\mathrm{N}_{2}$ after $\mathrm{H}_{2}$ reduction at $900{ }^{\circ} \mathrm{C}$ in order to ensure that surface $\mathrm{ReO}_{x}$ is not formed. The extended XAFS (EXAFS) analysis was carried out using the REX ver. 2.5 program (RIGAKU). The Fourier transformation of the $k^{3}$-weighted EXAFS from $k$ space to $R$ space was performed over a $k$ range of 3-12 $\AA^{-1}$. Curve-fitting analysis was carried out using the parameters for the $\mathrm{Re}-\mathrm{O}$ and $\mathrm{Re}-$ Re shells provided by FEFF6.

XPS was recorded on an EA 125 X-ray photoelectron spectrometer (Omicron) having a modified UHV chamber employing Mg Ka radiation (1253.6 eV). Binding energies calibration were accomplished by using the $\mathrm{O} 1 \mathrm{~s}$ peak energy $(532.0 \mathrm{eV})$ of $\mathrm{TiO}_{2}$. Samples were subjected to measurements after reduction under a flow of $\mathrm{H}_{2}$ in a glove box filled with $\mathrm{N}_{2}$. The glove box was connected directly to the XPS chamber to avoid exposing the reduced samples to air.

\section{Catalytic hydrogenation reactions}

The following procedure is representative for reductions of carboxylic acids and amides. After being reduced with $\mathrm{H}_{2}$ at $T=500{ }^{\circ} \mathrm{C}$ (cf. Preparation of the Catalysts), the catalyst ( $2 \mathrm{~mol} \%$ with respect to the loaded metal), and a mixture of 3-phenylpropionic acid $(1.0 \mathrm{mmol})$ and $n$-dodecane (0.29 mmol) were added to an autoclave with $10 \mathrm{~mL}$ volume. The mixture was stirred magnetically $\left(T=140^{\circ} \mathrm{C}, p_{\mathrm{H} 2}=5 \mathrm{MPa}\right)$. The resultant mixture was diluted with 2-propanol and then analyzed by using GC (Shimadzu GC2014 having a capillary column UA+-1 from Frontier Laboratories Ltd.) and GC-MS (Shimadzu GCMS-QP2010 with the same capillary column). GC analyses with $n$-dodecane as the internal standard were employed for yield determination. Yields are given relative to the starting substrate. Conversion was calculated using the following equation (1).

Conversion $(\%)=\left(1-\frac{\text { Amount of detected substrate }(\mathrm{mmol})}{\text { Amount of loaded substrate }(\mathrm{mmol})}\right) \times 100$

The following procedure is representative for reduction of triglycerides. After being reduced with $\mathrm{H}_{2}$ at $T=500{ }^{\circ} \mathrm{C}$ (cf. Preparation of the Catalysts), the catalyst (2 mol\% with respect to the loaded Re for the number of carboxylic acid ester moieties), and a mixture of tristearin (0.33 $\mathrm{mmol})$ and $n$-dodecane $(0.29 \mathrm{mmol})$ were added to the autoclave. The reaction mixture was stirred magnetically $\left(T=220^{\circ} \mathrm{C}, p_{\mathrm{H} 2}=5 \mathrm{MPa}\right)$. The resultant mixture was analyzed by using the 
GC and GC-MS. GC analyses with $n$-dodecane as the internal standard were employed for yield determination. Yields are given relative to the number of carboxylic acid ester moieties. Detailed procedures for product separations and NMR analysis is given in the Supporting Information. 


\section{Results and discussion}

\section{Characterization of the supported Re catalysts}

$\mathrm{Re}(5) / \mathrm{TiO}_{2}, \operatorname{Re}(5) / \mathrm{Al}_{2} \mathrm{O}_{3}, \mathrm{Re}(5) / \mathrm{SiO}_{2}$, and $\mathrm{Re}(5) /$ Carbon catalysts were characterized by using in situ XRD, STEM, and XAFS analysis. Figure 1 shows the XRD patterns for the catalysts arising from measurements carried out under a flow of $5 \% \mathrm{H}_{2} / \mathrm{N}_{2}\left(30 \mathrm{~mL} \mathrm{~min}^{-1}\right)$. The XRD pattern of the $\mathrm{Re}(5) / \mathrm{TiO}_{2}$ catalyst is essentially identical to that of pristine $\mathrm{TiO}_{2}$ even after $\mathrm{H}_{2}$ reduction at $500{ }^{\circ} \mathrm{C}$. Peaks from Re species were also not observed for $\operatorname{Re}(5) / \mathrm{Al}_{2} \mathrm{O}_{3}$ and $\operatorname{Re}(5) / \mathrm{Carbon}$. On the other hand, peaks from Re species are present in the XRD pattern of $\mathrm{Re}(5) / \mathrm{SiO}_{2}$ after pretreatment with $\mathrm{H}_{2}$ at $500{ }^{\circ} \mathrm{C}$. The results indicate that $\mathrm{Re}$ forms crystalline and sufficiently large species that can be observed by using XRD only on the $\mathrm{SiO}_{2}$ support. The ex situ XRD patterns for these catalysts (Figure $\mathbf{S} 1$ in the Supporting Information) are consistent with those arising from the in situ measurements.

Figure 2 shows bright field STEM (BF-STEM) images and high-angle annular dark-field STEM (HAADF-STEM) images of $\mathrm{Re}(5) / \mathrm{TiO}_{2}$, following exposure to air as a consequence of the experimental setup. Inspection of the images shows that $\mathrm{Re}$ on $\mathrm{TiO}_{2}$ is highly dispersed and has particle sizes below $2 \mathrm{~nm}$. Also, some Re species exist as clusters with a few Re atoms and single atoms in the $\mathrm{TiO}_{2}$ matrix. Viewing the HAADF-STEM images of $\operatorname{Re}(5) / \mathrm{Al}_{2} \mathrm{O}_{3}, \operatorname{Re}(5) / \mathrm{SiO}_{2}$, and $\mathrm{Re}(5) /$ Carbon, displayed in Fig. 3, shows that $\mathrm{Re}$ is relatively dispersed on the $\mathrm{Al}_{2} \mathrm{O}_{3}$ surface and Re clusters with sizes below $1 \mathrm{~nm}$ exist. In addition to these highly dispersed species, aggregated $\mathrm{Re}$ species with 2-5 nm sizes are present. In $\mathrm{Re}(5) / \mathrm{SiO}_{2}$ and $\mathrm{Re}(5) /$ Carbon, $\mathrm{Re}$ exists mainly in the form of aggregated particles with sizes larger than $5 \mathrm{~nm}$ although there still are some atomically dispersed Re. 


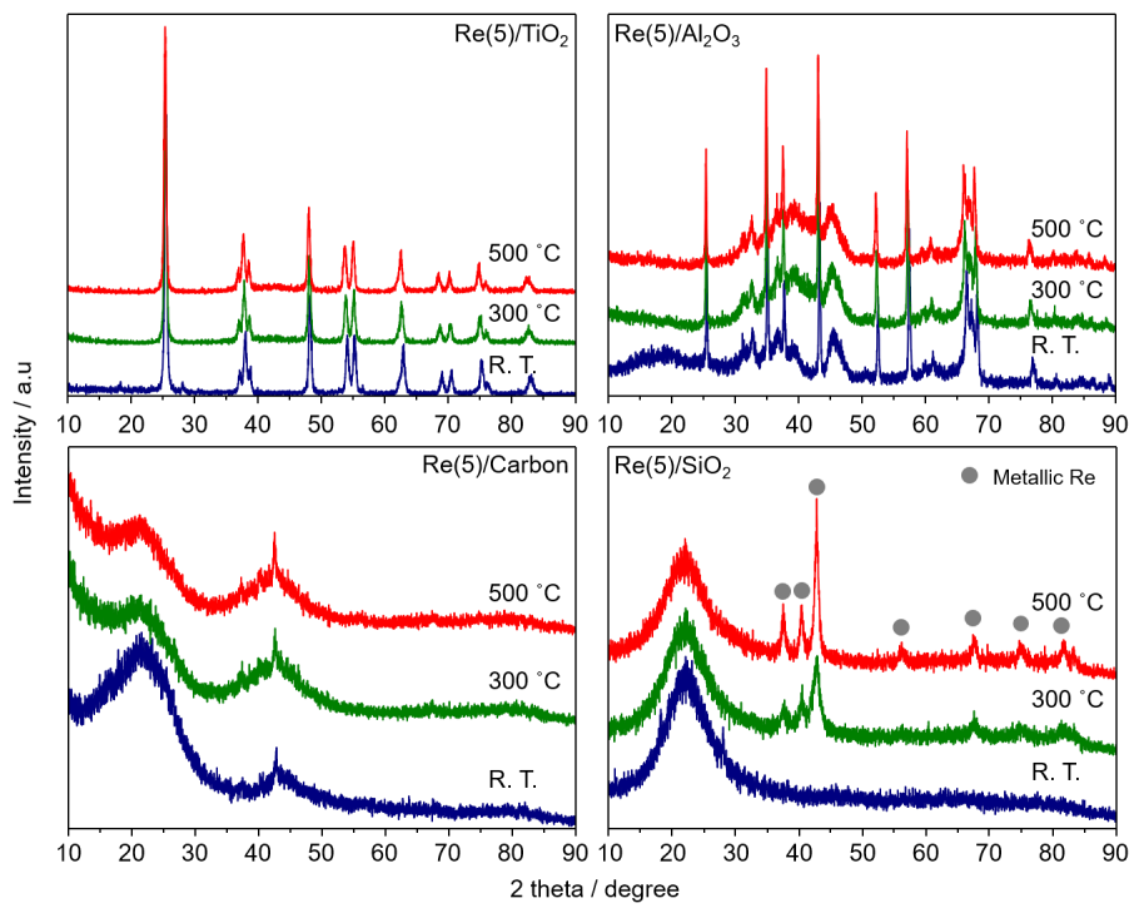

Figure 1. In situ XRD patterns of $\mathrm{Re}(5) / \mathrm{TiO}_{2}, \mathrm{Re}(5) / \mathrm{SiO}_{2}, \mathrm{Re}(5) / \mathrm{Al}_{2} \mathrm{O}_{3}$, and $\mathrm{Re}(5) / \mathrm{Carbon}$ measured under a flow of $5 \% \mathrm{H}_{2} / \mathrm{N}_{2}\left(30 \mathrm{~mL} \mathrm{~min}^{-1}\right)$ up to $500{ }^{\circ} \mathrm{C}$ with a heating rate of $10{ }^{\circ} \mathrm{C} / \mathrm{min}$.

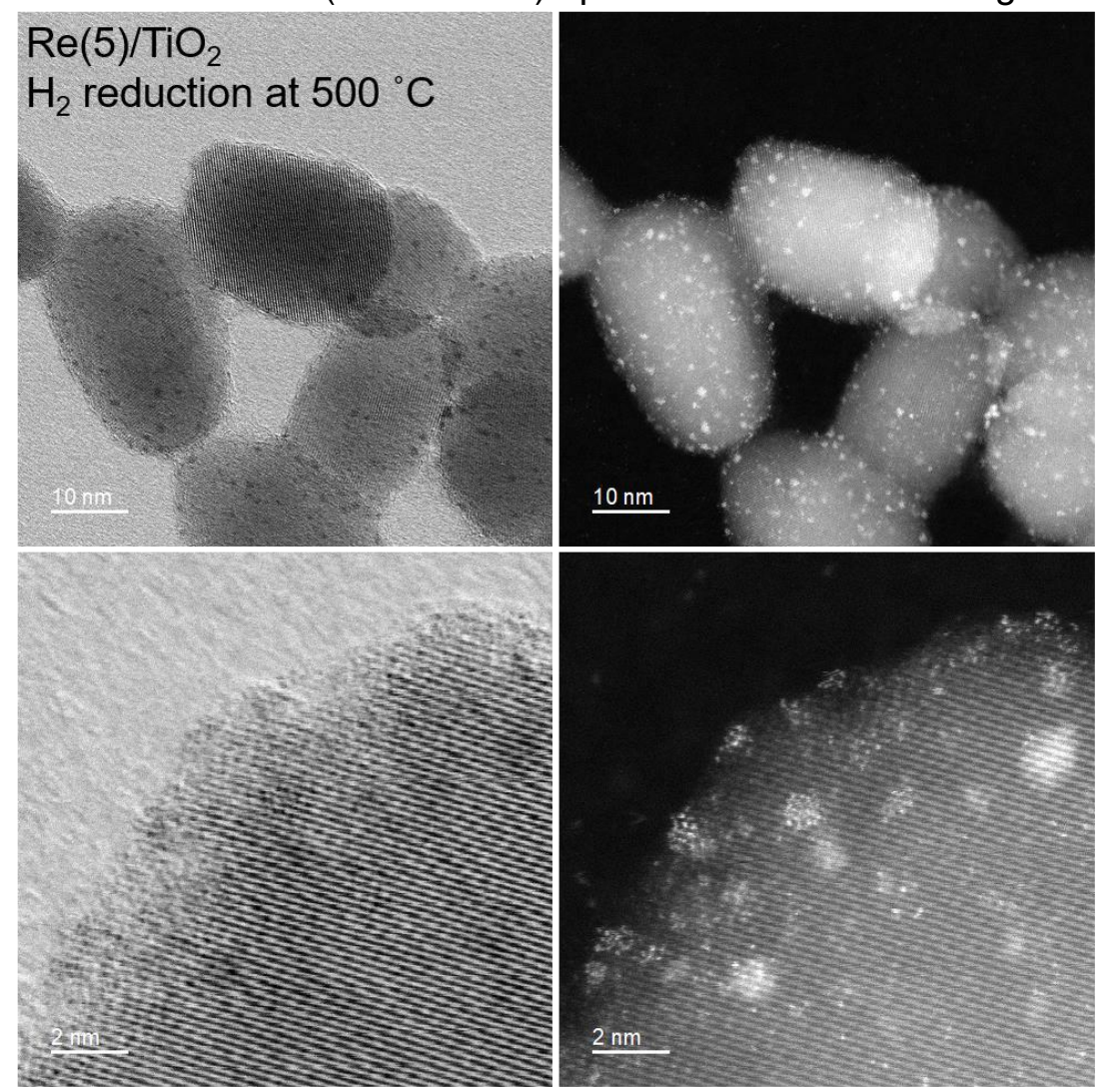

Figure 2. $\mathrm{BF}$ (left)- and HAADF(right)-STEM images for $\mathrm{Re}(5) / \mathrm{TiO}_{2}$. The $\mathrm{Re}(5) / \mathrm{TiO}_{2}$ sample was reduced at $500{ }^{\circ} \mathrm{C}$ under a flow of $\mathrm{H}_{2}$. Due to the experimental setup, the sample was exposed to air before measurements. 

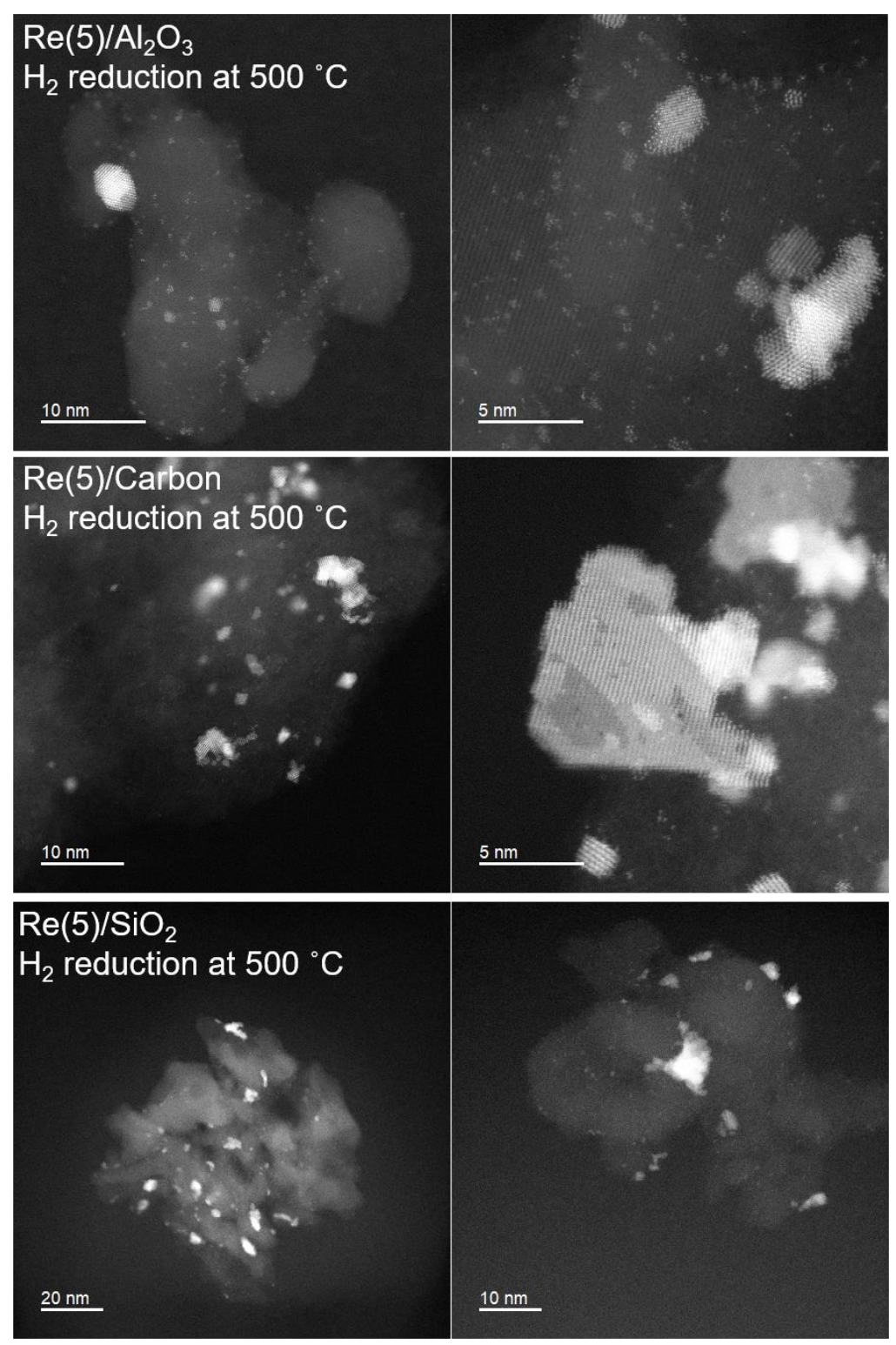

Figure 3. HAADF-STEM images for $\mathrm{Re}(5) / \mathrm{SiO}_{2}, \mathrm{Re}(5) / \mathrm{Al}_{2} \mathrm{O}_{3}$, and $\mathrm{Re}(5) /$ Carbon. All the catalysts were reduced at $500{ }^{\circ} \mathrm{C}$ under a flow of $\mathrm{H}_{2}$. Due to the experimental setup, the samples were exposed to air before the measurements.

Figure 4 shows Re L3-edge XANES and EXAFS spectra. The in situ XANES spectra of the Re samples (Fig. 4A-E) were recorded under a flow of $5 \% \mathrm{H}_{2} / \mathrm{He}\left(100 \mathrm{~mL} \mathrm{~min}^{-1}\right)$ at various temperatures between $100-700{ }^{\circ} \mathrm{C}$ together with the spectra of reference compounds measured at room temperature. The XANES spectra of all the catalysts treated with $\mathrm{H}_{2}$ at temperatures up to $200{ }^{\circ} \mathrm{C}$ corresponded to that of $\mathrm{Re}_{2} \mathrm{O}_{7}$, indicating that the Re species in these samples were in the highest oxidation state (VII). The white line intensity for $\mathrm{Re}(5) / \mathrm{TiO}_{2}$ decreased by the $\mathrm{H}_{2}$ reduction at $300{ }^{\circ} \mathrm{C}$ while those of the other Re species decreased at $400{ }^{\circ} \mathrm{C}$. These results 
indicate that the valence states of the Re species decreased at $200-400^{\circ} \mathrm{C}$. It is worth mentioning here that $\mathrm{Re}$ on $\mathrm{TiO}_{2}$ starts to be reduced at the lowest temperature (below $300{ }^{\circ} \mathrm{C}$ ) among the samples measured in this study. A comparison of XANES spectra of Re on different supports is given in Fig. 4E. The spectra were recorded using samples treated with $\mathrm{H}_{2}$ at $500{ }^{\circ} \mathrm{C}$ because catalysts treated in this manner have the highest activities in hydrogenation reactions of carboxylic acid derivatives. ${ }^{29,30}$ The results show the edge position lie between those for metallic $\mathrm{Re}$ and $\mathrm{ReO}_{2}$ as references while the white line intensities are all higher than that of $\mathrm{ReO}_{2}$. These results indicate that all the catalysts contain oxidized Re species. In addition, as shown in Fig. S2, a prominent peak was observed at ca. $10549 \mathrm{eV}$ and appeared with the order of $\mathrm{Re}(5) / \mathrm{TiO}_{2}$ $<\mathrm{Re}(5) / \mathrm{Al}_{2} \mathrm{O}_{3}<\mathrm{Re}(5) / \mathrm{Carbon}<\mathrm{Re}(5) / \mathrm{SiO}_{2}$. It was reported that the peak intensity increases with increase in the Re particle sizes. ${ }^{50}$

Fourier transforms (FT) of $k^{3}$-weighted EXAFS spectra of the supported Re catalysts are displayed in Fig. 4F. The spectra were recorded at room temperature on samples not exposed to air after $\mathrm{H}_{2}$ pretreatment at $500{ }^{\circ} \mathrm{C}$. The distances and coordination numbers (CNs) for the $\mathrm{Re}-\mathrm{O}$ and Re-Re shells were determined by curve-fitting analysis of the EXAFS data (Table 1). The EXAFS spectra of $\mathrm{Re}(5) / \mathrm{TiO}_{2}$ and $\mathrm{Re}(5) / \mathrm{Al}_{2} \mathrm{O}_{3}$ contain features associated with both $\mathrm{Re}-\mathrm{O}$ and $\mathrm{Re}-\mathrm{Re}$. $\mathrm{Re}(5) / \mathrm{TiO}_{2}$ has large $\mathrm{Re}-\mathrm{O}$ contributions, suggesting that the Re species on $\mathrm{TiO}_{2}$ is highly dispersed. On the other hand, the spectra of $\mathrm{Re}(5) / \mathrm{SiO}_{2}$ and $\mathrm{Re}(5) /$ Carbon are comprised of a single Re-Re contribution at $2.75 \AA$ with a $\mathrm{CN}$ of 10.4 and 10.7 , respectively. The high CNs of $\mathrm{Re}-\mathrm{Re}$ observed for $\mathrm{Re}(5) / \mathrm{SiO}_{2}$ and $\mathrm{Re}(5) / \mathrm{C}$ indicate that most of the $\mathrm{Re}$ species form large Re particles. These observations are consistent with results from XRD and STEM measurements.

XANES spectra showed that all the Re species have valence higher than 0 whereas EXAFS spectra showed the Re-Re contribution which suggests formation of metallic $\mathrm{Re}$ particles. The Re species in those catalysts would be mixture of Re particles and highly dispersed Re species which should have $\mathrm{Re}-\mathrm{O}$ bond. Although the fraction of oxidized $\mathrm{Re}$ species estimated from the XANES spectra was not so different among the studied catalysts, results of EXAFS showed strong support dependence on the dispersion of Re. True reasons for this inconsistency are not clear. However, origins of the observed XANES spectra would be related to not only the valence states but also the complex structures of Re. ${ }^{50}$ 
Ti K-edge XANES spectra of $\mathrm{Re}(5) / \mathrm{TiO}_{2}$ were also recorded on samples treated with $\mathrm{H}_{2}$ at temperatures up to $700{ }^{\circ} \mathrm{C}$ (Figure 5). Inspection of the spectra shows that the edge position shifts slightly to lower energy with increasing reduction temperature, which indicates that $\mathrm{Ti}$ species in the support are also reduced by the $\mathrm{H}_{2}$ pretreatment. Figure $\mathbf{S} 3$ shows $\mathrm{H}_{2}$-TPR profiles of $\mathrm{Re}(5) / \mathrm{TiO}_{2}, \mathrm{Re}(5) / \mathrm{SiO}_{2}, \mathrm{Re}(5) / \mathrm{Al}_{2} \mathrm{O}_{3}$, and $\mathrm{Re} /$ Carbon before the $\mathrm{H}_{2}$ reduction treatment. The peaks corresponding to the $\mathrm{H}_{2}$ consumption appeared around temperatures of 200-400 ${ }^{\circ} \mathrm{C}$ for all the samples. It was also found that the $\mathrm{H}_{2}$ consumption peak for $\mathrm{Re}(5) / \mathrm{TiO}_{2}$ appeared at the lowest temperature and that for $\mathrm{Re}(5) / \mathrm{Al}_{2} \mathrm{O}_{3}$ appeared at the highest temperature among the samples tested. These features are consistent with the results of in situ Re $\mathrm{L}_{3}$-edge XANES spectra measured during the $\mathrm{H}_{2}$ reduction.
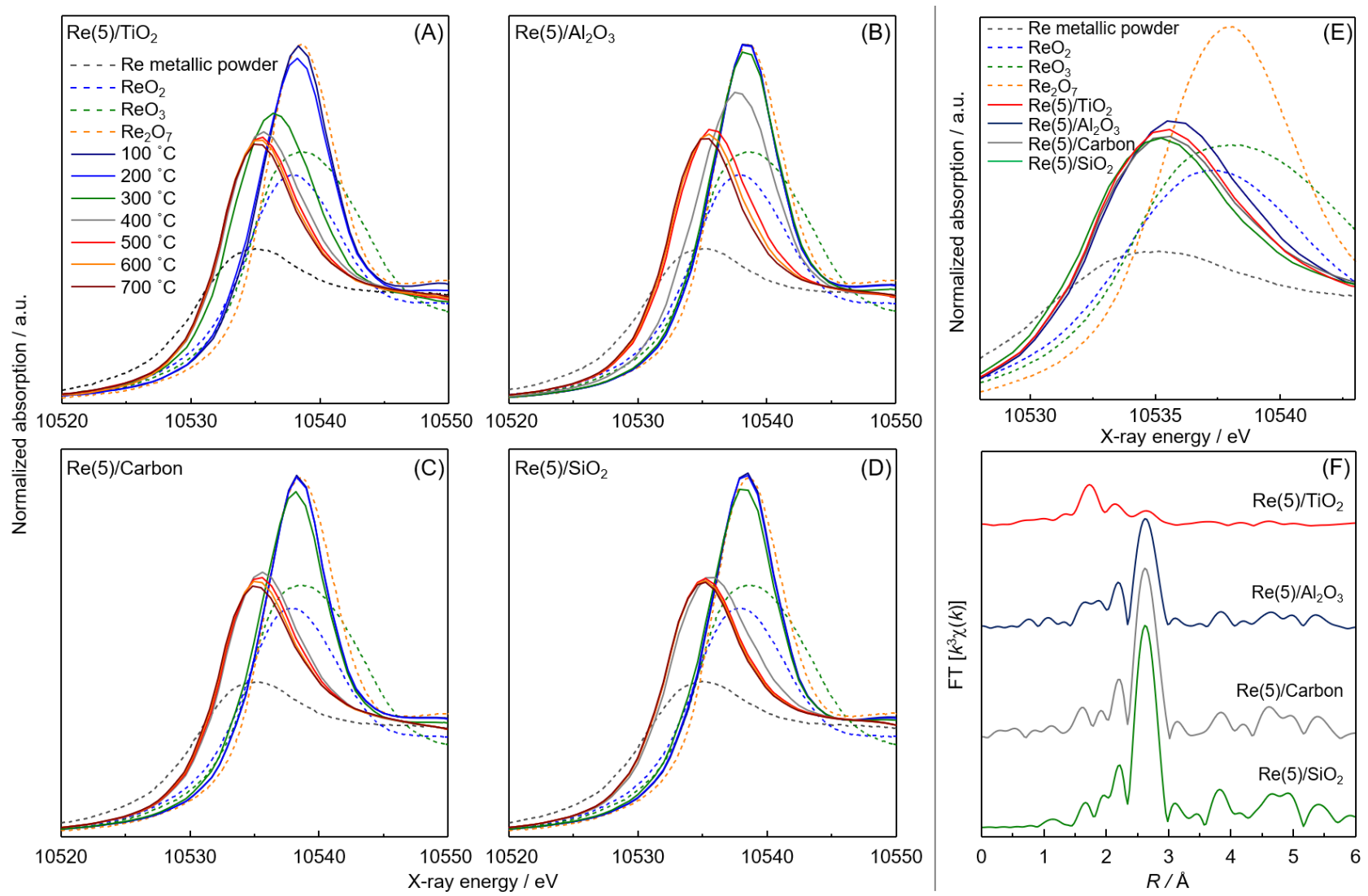

Figure 4. In situ $\mathrm{Re} \mathrm{L}_{3}$-edge XANES spectra of (A) $\mathrm{Re}(5) / \mathrm{TiO}_{2}$, (B) $\mathrm{Re}(5) / \mathrm{Al}_{2} \mathrm{O}_{3}$, (C) $\operatorname{Re}(5) / \mathrm{Carbon}$, and (D) $\operatorname{Re}(5) / \mathrm{SiO}_{2}$. Samples were heated under a flow of $5 \% \mathrm{H}_{2} / \mathrm{He}\left(100 \mathrm{~mL} \mathrm{~min}^{-1}\right)$ up to $700{ }^{\circ} \mathrm{C}$ with a heating rate of $10^{\circ} \mathrm{C} / \mathrm{min}$. XANES spectra for reference samples were recorded at room temperature. (E) Comparison of XANES spectra of Re on different supports which were measured at $500{ }^{\circ} \mathrm{C}$ under the flow of $5 \% \mathrm{H}_{2} / \mathrm{He}\left(100 \mathrm{~mL} \mathrm{~min}^{-1}\right)$. (F) Fourier transforms of $k^{3}$-weighted EXAFS oscillations recorded at room temperature. The samples were not exposed to air after the $\mathrm{H}_{2}$ reduction at $500{ }^{\circ} \mathrm{C}$ by sealing the samples in a glove bag filled with $\mathrm{N}_{2}$. 
Table 1. Curve-fitting analysis of the $\mathrm{Re} \mathrm{L}_{3}$-edge EXAFS of the $\mathrm{Re}(5) / \mathrm{TiO}_{2}, \mathrm{Re}(5) / \mathrm{Al}_{2} \mathrm{O}_{3}, \mathrm{Re}(5) / \mathrm{Carbon}$, and $\mathrm{Re}(5) / \mathrm{SiO}_{2}$ catalysts.

\begin{tabular}{llllll}
\hline Sample & Shell & $\mathrm{CN}^{a}$ & $R(\AA))^{\mathrm{b}}$ & $\sigma(\AA)^{\mathrm{c}}$ & $\mathrm{R}_{\mathrm{f}}(\%)^{\mathrm{d}}$ \\
\hline $\operatorname{Re}(5) / \mathrm{TiO}_{2}$ & $\mathrm{Re}$ & 3.4 & 2.62 & 0.09 & 4.1 \\
& $\mathrm{O}$ & 2.7 & 2.02 & 0.09 & \\
$\operatorname{Re}(5) / \mathrm{Al}_{2} \mathrm{O}_{3}$ & $\mathrm{Re}$ & 8.6 & 2.74 & 0.08 & 3.3 \\
& $\mathrm{O}$ & 2.0 & 1.98 & 0.09 & \\
$\operatorname{Re}(5) / \mathrm{Carbon}$ & $\mathrm{Re}$ & 10.4 & 2.75 & 0.07 & 2.3 \\
$\operatorname{Re}(5) / \mathrm{SiO}_{2}$ & $\mathrm{Re}$ & 10.7 & 2.75 & 0.07 & 1.7
\end{tabular}

${ }^{a}$ Coordination number. ${ }^{b}$ Bond distance. ${ }^{c}$ Debye-Waller factor. ${ }^{d}$ Residual factor.

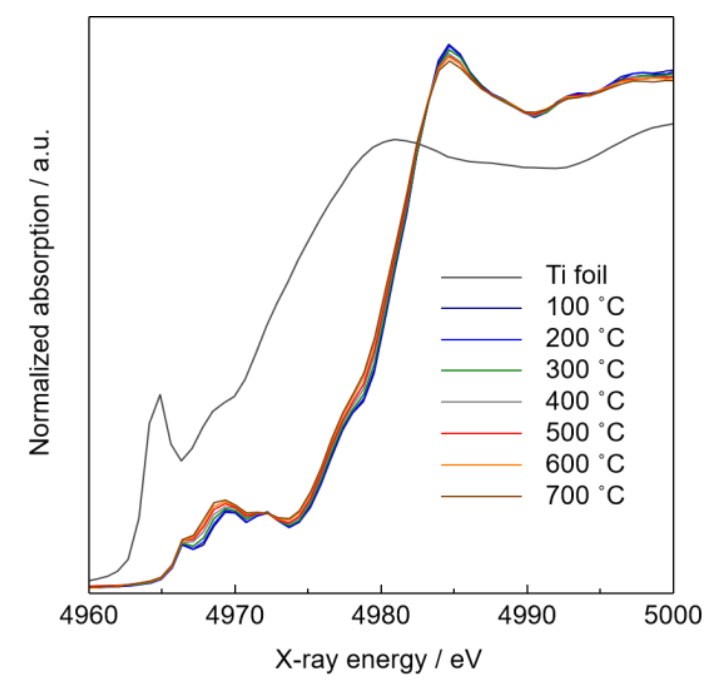

Figure 5. In situ Ti K-edge XANES spectra of $\mathrm{Re}(5) / \mathrm{TiO}_{2}$. A sample was heated under a flow of $5 \% \mathrm{H}_{2} / \mathrm{He}$ $\left(100 \mathrm{~mL} \mathrm{~min}^{-1}\right)$ up to $700{ }^{\circ} \mathrm{C}$ with a heating rate of $10^{\circ} \mathrm{C} / \mathrm{min}$. The spectrum of $\mathrm{Ti}$ foil was recorded at room temperature.

XPS analysis was performed in order to gain further information about the oxidation states of the Re species on $\mathrm{TiO}_{2}$. Figure 6 shows spectra of the $\mathrm{Re} 4 \mathrm{f}$ region of $\mathrm{Re}(5) / \mathrm{TiO}_{2}$ before and after reduction with $\mathrm{H}_{2}$ at $500{ }^{\circ} \mathrm{C}$, along with a spectrum after $\mathrm{H}_{2}$ reduction at $700{ }^{\circ} \mathrm{C}$. It should be noted that spectra were recorded on reduced samples directly after $\mathrm{H}_{2}$ reduction without being exposed to air by using a glove box that is connected to the XPS chamber. The spectra are comprised of signals associated with both $4 f_{7 / 2}$ and $4 f_{5 / 2}$ core levels. The spectrum of $\mathrm{Re}(5) / \mathrm{TiO}_{2}$ prior to $\mathrm{H}_{2}$ reduction contains two Re components in $4 \mathrm{f}_{7 / 2}$ peaks at ca $46.1 \mathrm{eV}$ and ca $44.0 \mathrm{eV}$, which are attributed to $\mathrm{Re}^{7+}$ and $\mathrm{Re}^{6+}$ species, respectively. ${ }^{30}$ In contrast, a peak at ca $40.7 \mathrm{eV}$ is present in the spectrum of $\mathrm{Re}(5) / \mathrm{TiO}_{2}$ after $\mathrm{H}_{2}$ reduction at $500{ }^{\circ} \mathrm{C}$, which is assigned to a $4 \mathrm{f}_{7 / 2}$ peak of a $\mathrm{Re}^{0}$ species. ${ }^{61}$ In addition, contributions from oxidized Re species such as $\mathrm{Re}^{4+}, \mathrm{Re}^{2+}$, and $\mathrm{Re}^{\delta+}(\delta \sim 1)$ can be present in the spectra of the samples even after $\mathrm{H}_{2}$ 
reduction. ${ }^{47}$ Moreover, analysis of the spectra shows that $\mathrm{Re}$ species in $\mathrm{Re}(5) / \mathrm{TiO} 2$ exist in further reduced states after $\mathrm{H}_{2}$ reduction at $700{ }^{\circ} \mathrm{C}$. These results indicate that, in a manner that is consistent with the XAFS observations, $\mathrm{H}_{2}$ reduction induces formation of low-valent $\mathrm{Re}$ species including those in the metallic state. Importantly, however, not all the Re species are reduced to the metallic state even when $\mathrm{H}_{2}$ reduction is carried out at $700{ }^{\circ} \mathrm{C} .{ }^{30}$

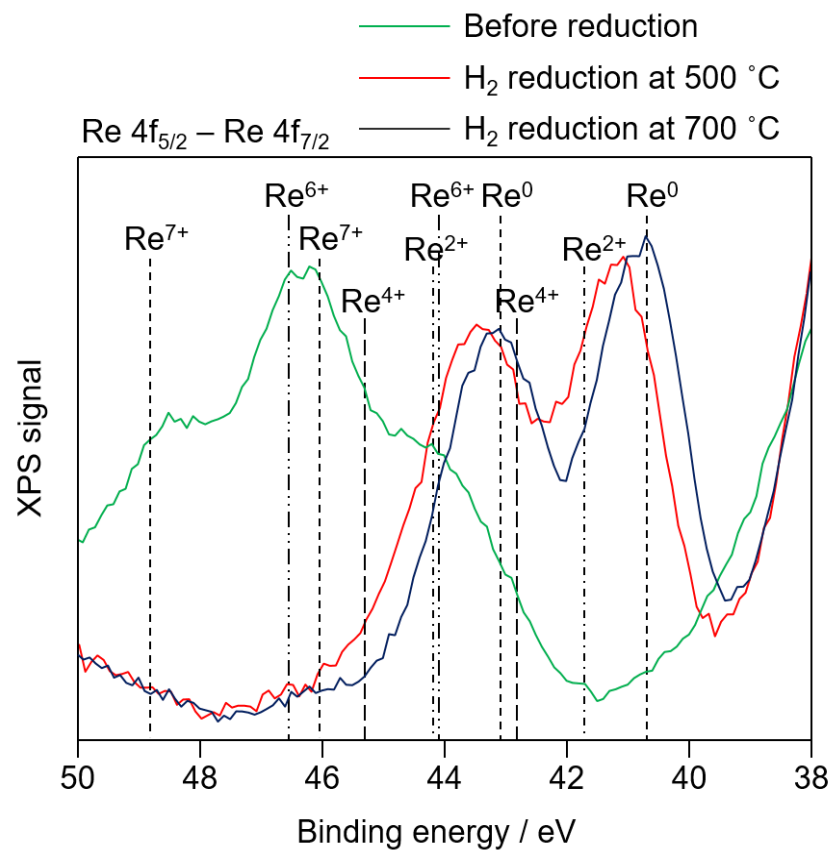

Figure 6. XP spectra of the $\mathrm{Re} 4 \mathrm{f}$ region of $\mathrm{Re}(5) / \mathrm{TiO}_{2}$ before and after the reduction with $\mathrm{H}_{2}$ at 500 and $700{ }^{\circ} \mathrm{C}$. The spectra before and after the reduction $700{ }^{\circ} \mathrm{C}$ are from our previous report. ${ }^{30}$ 


\section{Selective hydrogenation of carboxylic acids and their derivatives}

Hydrogenations reactions of 3-phenylpropionic acid (1a) were explored in order to assess the activities of the various catalysts investigated by using various characterization methods. Following pretreatment of the catalysts with $\mathrm{H}_{2}$ at $500{ }^{\circ} \mathrm{C}$, reactions were conducted using 1 $\mathrm{mmol}$ of $1 \mathrm{a}$ and $2 \mathrm{~mol} \%$ (based on metal content) of the catalysts in a stainless autoclave (10 $\mathrm{mL}$ ) under $5 \mathrm{MPa} \mathrm{H} \mathrm{H}_{2}$ at $140^{\circ} \mathrm{C}$ for $3 \mathrm{~h}$. The results, summarized in Table 2, show that the reaction promoted by $\mathrm{Re}(5) / \mathrm{TiO}_{2}$ produces 3-phenylpropanol (2a) and the corresponding ester (3a), which is formed via an esterification reaction of the starting carboxylic acid with the formed alcohol (Entry 1). Hydrogenation reaction of $\mathbf{1 a}$ catalyzed by $\mathrm{Pt}(5) / \mathrm{TiO}_{2}$ also generates $\mathbf{2 a}$ and 3a in relatively high yields. In contrast, use of $\mathrm{Pt}(5) / \mathrm{TiO}_{2}$ as a catalyst leads to competitive formation of undesired products such as 3-cyclohexyl-propionic acid (4a), 3-cyclohexyl-propan1-ol (5a) and 3-cyclohexyl-propyl 3-cyclohexyl-propioniate (6a), which are produced by benzene ring reductive dearomatization reactions (Entry 2). These products are also formed in reactions promoted by other precious metal ( $\mathrm{Ir}, \mathrm{Ru}, \mathrm{Rh}$, and $\mathrm{Pd}$ ) containing catalysts and propylcyclohexane is generated when the reaction time is extended(Entries 3-6). ${ }^{29}$ In processes in which $\mathrm{Re}$ catalysts such as $\mathrm{Re}(5) / \mathrm{SiO}_{2}, \mathrm{Re}(5) / \mathrm{Al}_{2} \mathrm{O}_{3}$, and $\mathrm{Re}(5) / C a r b o n$ are employed, only $2 a$ and $\mathbf{3 a}$ are produced (Entries 7-9), suggesting that Re does not catalyze reactions that form dearomatized products. Although reactions catalyzed by these Re-based catalysts display good selectivity for reduction of the carboxylic acid group rather than the aromatic moiety, the yields are highest when $\mathrm{Re}(5) / \mathrm{TiO}_{2}$ is used. We also found that the desired alcohol $\mathbf{2 a}$ is efficiently generated via a pathway involving initial formation of 3-phenylpropyl 3-phenyl-propionate (3a) in yields that reach $97 \%$ after $24 \mathrm{~h} .{ }^{29}$ The results clearly demonstrate that the combination of $\mathrm{Re}$ as the catalytically active species and $\mathrm{TiO}_{2}$ as the support leads to a catalytic system that promotes selective and efficient hydrogenations of carboxylic acids to form alcohols, and that this system does not promote generation of undesired side-products such as alkanes and dearomatized compounds. It should also be noted that we have confirmed that the hydrogenation reactions proceed with heterogeneous nature in our previous studies. ${ }^{29,30}$ 
Table 2. Heterogeneous catalytic hydrogenation of 3-phenylpropionic acid. ${ }^{a}$

\begin{tabular}{|c|c|c|c|c|c|c|c|}
\hline \multirow{2}{*}{ Entry } & \multirow{2}{*}{ Catalysts } & \multirow{2}{*}{ Conv. (\%) } & \multicolumn{5}{|c|}{ Yield (\%) } \\
\hline & & & $2 a$ & $3 a$ & $4 a$ & $5 a$ & $6 a$ \\
\hline 1 & $\mathrm{Re}(5) / \mathrm{TiO}_{2}$ & 36 & 18 & 18 & 0 & 0 & 0 \\
\hline 2 & $\mathrm{Pt}(5) / \mathrm{TiO}_{2}$ & 66 & 13 & 24 & 20 & 3 & 6 \\
\hline 3 & $\operatorname{Ir}(5) / \mathrm{TiO}_{2}$ & 6 & 0 & 6 & 0 & 0 & 0 \\
\hline 4 & $\mathrm{Ru}(5) / \mathrm{TiO}_{2}$ & 1 & 0 & 1 & 0 & 0 & 0 \\
\hline 5 & $\mathrm{Rh}(5) / \mathrm{TiO}_{2}$ & 66 & 0 & 0 & 65 & 0 & 1 \\
\hline 6 & $\mathrm{Pd}(5) / \mathrm{TiO}_{2}$ & 52 & 0 & 0 & 52 & 0 & 0 \\
\hline 7 & $\mathrm{Re}(5) / \mathrm{Al}_{2} \mathrm{O}_{3}$ & 13 & 7 & 6 & 0 & 0 & 0 \\
\hline 8 & $\operatorname{Re}(5) /$ Carbon & 13 & 5 & 8 & 0 & 0 & 0 \\
\hline 9 & $\mathrm{Re}(5) / \mathrm{SiO}_{2}$ & 3 & 1 & 2 & 0 & 0 & 0 \\
\hline
\end{tabular}

Control experiments were conducted to identify the origin of the high selectivity of $\mathrm{Re}(5) / \mathrm{TiO}_{2}$ in catalyzing hydrogenation reactions that form alcohols rather than those lead to reduction of benzene rings. In our previous studies, we employed density functional theory (DFT) calculations to show that the selectivity of hydrogenations of carboxylic acid derivatives strongly depends on the relative adsorption affinities of substances containing benzene rings, and $\mathrm{COOH}$ or $\mathrm{COOCH}_{3}$ groups. ${ }^{29,30}$ In the present effort, we performed individual catalytic hydrogenation reactions of (i) propylbenzene, (ii) propylbenzene + lauric acid (dodecanoic acid), and (iii) propylbenzene + lauryl alcohol (dodecanol) using $\mathrm{Re}(5) / \mathrm{TiO}_{2}$ as the catalyst. The results displayed in Fig. 7 show that $\mathrm{Re}(5) / \mathrm{TiO}_{2}$ promotes hydrogenation (dearomatization) of propylbenzene to form propylcyclohexane. However, when a mixture of propylbenzene and lauric acid is used, dearomatization reaction of the former substance does not take place while lauric acid is preferentially reduced to generate the corresponding alcohol and lauryl laurylate. Moreover, no reaction occurs using a mixture of propylbenzene and lauryl alcohol. These results show that $\mathrm{Re}(5) / \mathrm{TiO}_{2}$ is capable of promoting hydrogenation of benzene rings but this ability is suppressed in the presence of carboxylic acids and alcohols. This finding suggests that, owing to its oxophilic nature, ${ }^{37}$ Re species in the catalytic system strongly adsorb carboxylic acids and alcohols, which suppresses its participation in benzene ring reductive dearomatization reactions. 
In order to gain further information about the substrates governed selectivity phenomenon, control hydrogenation reactions of amides were explored (Figure 8). Individual catalytic hydrogenation reactions of (i) propylbenzene, (ii) propylbenzene $+\mathrm{N}, \mathrm{N}$-dimethyl-2phenylacetamide, and (iii) propylbenzene $+N, N$-Dimethylphenethylamine were performed using $\operatorname{Re}(5) / \mathrm{TiO}_{2}$ under more vigorous conditions $\left(p_{\mathrm{H} 2}=5 \mathrm{MPa}\right.$ and $T=200^{\circ} \mathrm{C}$ ). The results show that catalytic hydrogenation of propylbenzene occurs under these conditions to produce propylcyclohexane. On the other hand, hydrogenations of a mixture of propylbenzene and $\mathrm{N}, \mathrm{N}$ dimethyl-2-phenylacetamide, and a mixture of propylbenzene $+\mathrm{N}, \mathrm{N}$-Dimethylphenethylamine do not lead to formation of products arising by reductive dearomatization. Rather, selective hydrogenation of the amide moiety occurs to generate the corresponding amine. The results, which are in accord with those coming from studies of hydrogenation reactions of propylbenzene, lauric acid, and lauryl alcohol described above, show that the presence of amide or amine groups suppresses undesired dearomatization reactions. 

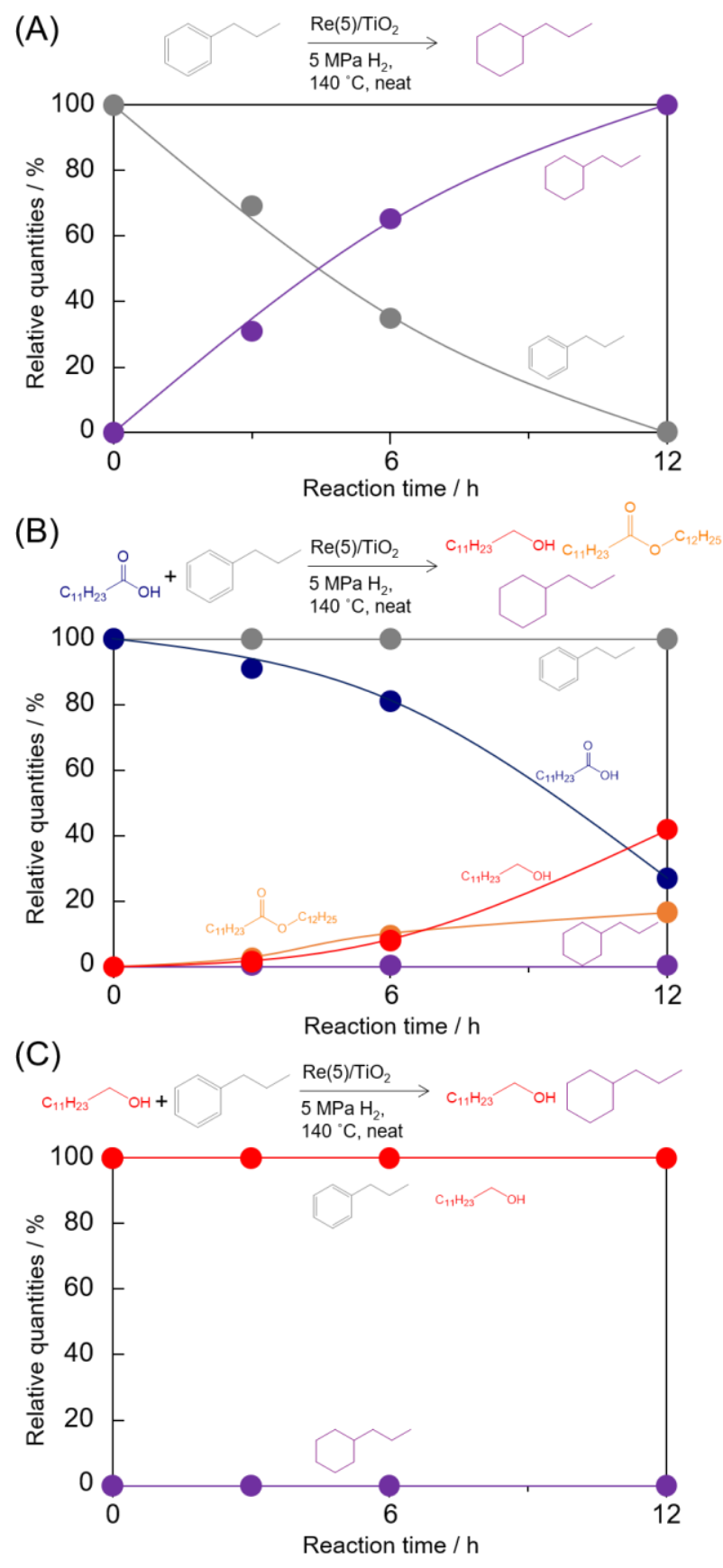

Figure 7. Catalytic hydrogenation of $(A)$ propylbenzene, $(B)$ propylbenzene + lauric acid (dodecanoic acid), and (C) propylbenzene + lauryl alcohol (dodecanol) over $\operatorname{Re}(5) / \mathrm{TiO}_{2}$. Reaction conditions: $2 \mathrm{~mol} \%$ $\mathrm{Re}, 1 \mathrm{mmol}$ of each substrate, no solvent, $p_{\mathrm{H} 2}=5 \mathrm{MPa}, T=140^{\circ} \mathrm{C}$. Yields were determined by $\mathrm{GC}$ using $n$-octane as the internal standard. 

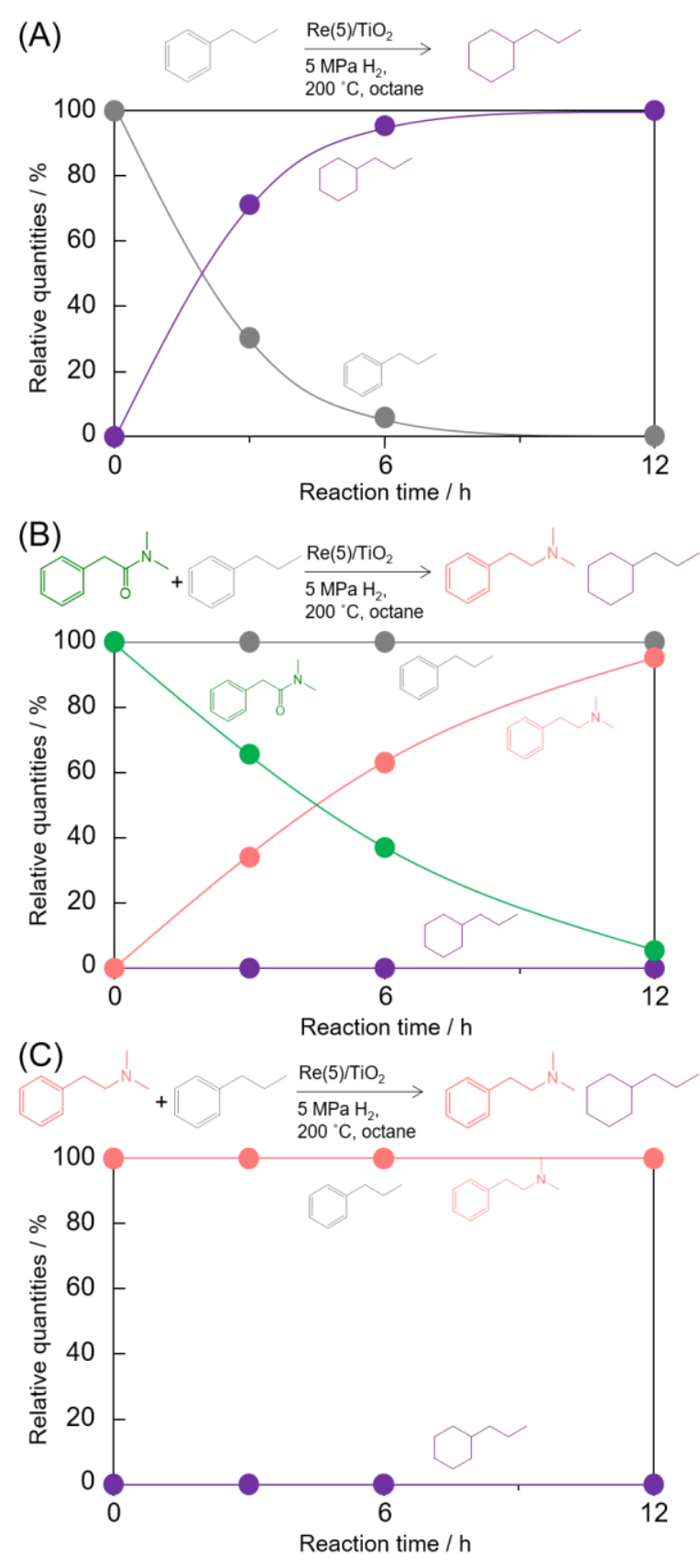

Figure 8. Catalytic hydrogenation of (A) propylbenzene, (B) propylbenzene $+N, N$-dimethyl-2phenylacetamide, and (C) propylbenzene $+N, N$-Dimethylphenethylamine over $\mathrm{Re}(5) / \mathrm{TiO}_{2}$. Reaction conditions: $2 \mathrm{~mol} \% \mathrm{Re}, 1 \mathrm{mmol}$ of each substrate, $1 \mathrm{~mL}$ of octane, $p_{\mathrm{H} 2}=5 \mathrm{MPa}, T=200{ }^{\circ} \mathrm{C}$. Yields were determined by GC using $n$-octane as the internal standard.

Next, the effect of $\mathrm{H}_{2}$ pressure and concentration of the carboxylic acid on the rate of the $\mathrm{Re}(5) / \mathrm{TiO}_{2}$ promoted hydrogenation of 3-phenylpropionic acid in $n$-octane was investigated (Fig. 9). The hydrogenation rate was defined as the sum of the alcohol formation rate and one half of the ester formation rate. The results show that the rate of hydrogenation increases with 
increasing $\mathrm{H}_{2}$ pressure. The reaction order with respect to $\mathrm{H}_{2}$ pressure was calculated to be +0.88 , which suggests that $\mathrm{H}_{2}$ is involved in a kinetically important step. On the other hand, the reaction order with respect to 3 -phenylpropionic acid concentration was calculated to be +0.03 , indicating that the carboxylic acid is strongly adsorbed on the surface of the $\mathrm{Re}(5) / \mathrm{TiO}_{2}$ catalyst. This observation is in agreement with those made in the selectivity experiments described above.
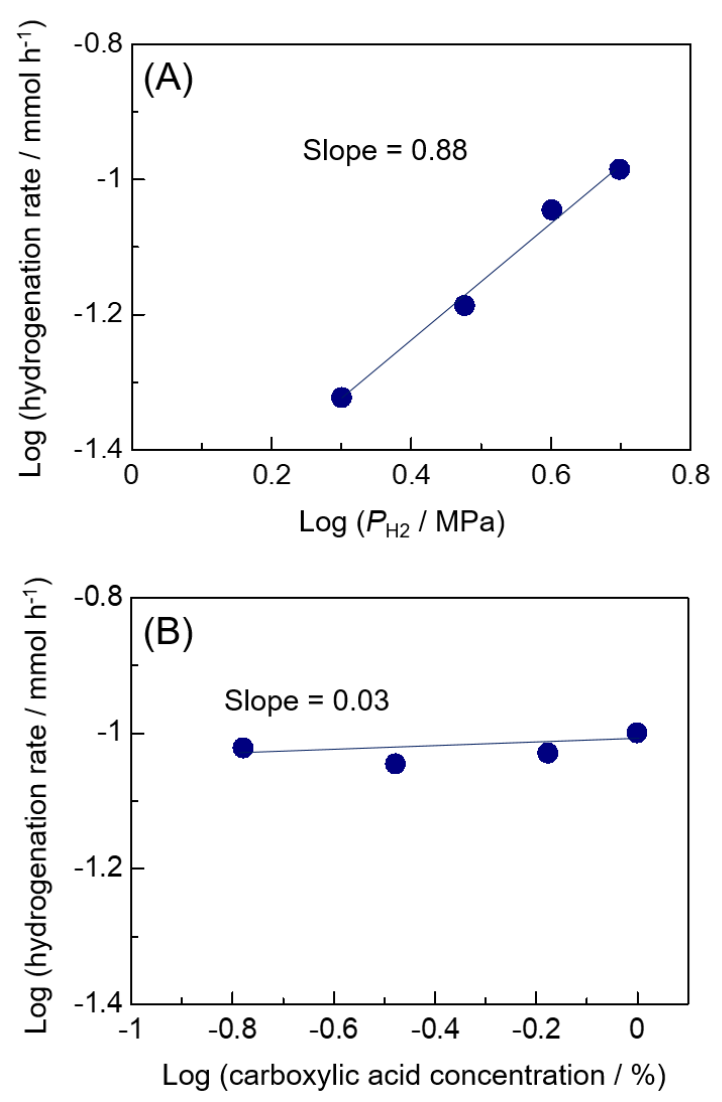

Figure 9. Effect of (A) the $\mathrm{H}_{2}$ pressure and (B) 3-phenylpropionic acid concentration on the rate of hydrogenation of 3-phenylpropionic acid catalyzed by $\mathrm{Re}(5) / \mathrm{TiO}_{2}$. Hydrogenation rate $=$ alcohol formation rate plus one half the ester formation rate. Pre-treatment: $\mathrm{H}_{2}\left(30 \mathrm{~mL} \mathrm{~min}{ }^{-1}\right), 500{ }^{\circ} \mathrm{C}, 0.5 \mathrm{~h}$; reaction conditions: $2 \mathrm{~mol} \% \mathrm{Re}, 1 \mathrm{mmol} 3$-phenylpropionic acid, $1 \mathrm{~mL} n$-octane as a solvent, $140{ }^{\circ} \mathrm{C}, 3 \mathrm{~h}$.

Hydrogenation reactions of 3-phenylpropionic acid using $\mathrm{Re}(\mathrm{x}) / \mathrm{TiO}_{2}(\mathrm{x}=0.2,1,5,10$, and $20 \mathrm{wt} \%$ ) were conducted in order to determine the optimal catalyst loading and to investigate the effect of the size of the Re species on the process (Figure 10A). The highest rate of hydrogenation was achieved using $\mathrm{Re}(5) / \mathrm{TiO}_{2}$. The results indicate that the hydrogenation process occurs more efficiently when the catalytic system contains Re species of sub-nanometer to a few nanometer sizes (see HAADF-STEM images of $\mathrm{Re}(\mathrm{x}) / \mathrm{TiO}_{2}$ in Fig. 11). We also explored hydrogenation reactions of 3 -phenylpropionic acid promoted by $\mathrm{Re}(5) / \mathrm{TiO}_{2}$ following 
pretreatment with $\mathrm{H}_{2}$ at different temperatures $\left(200,300,500,700\right.$, and $\left.900{ }^{\circ} \mathrm{C}\right)$. The results displayed in Fig. $10 \mathrm{~B}$ show that $\operatorname{Re}(5) / \mathrm{TiO}_{2}$, pre-treated at $500{ }^{\circ} \mathrm{C}$ with $\mathrm{H}_{2}$, is optimal for this process. These observations along with those made in the catalyst characterization studies using techniques such as XANES and XPS demonstrate that the average oxidation state of the Re species that promote hydrogenation should be higher than 0 and below +4 . At this time, we do not know the precise nature of the catalytically active Re species, and the catalyst may contain a variety of $\mathrm{Re}$ species in different oxidation states. We also cannot exclude the possibility that these mixtures of Re species in different oxidation states and the interfaces between them are required for the efficient progression of the reaction. It should also be noted that reductive pretreatment at temperatures beyond $500{ }^{\circ} \mathrm{C}$ leads to sintering of the Re species (see HAADF-STEM images in Fig. 12) and a lowering of the activity of the catalyst.
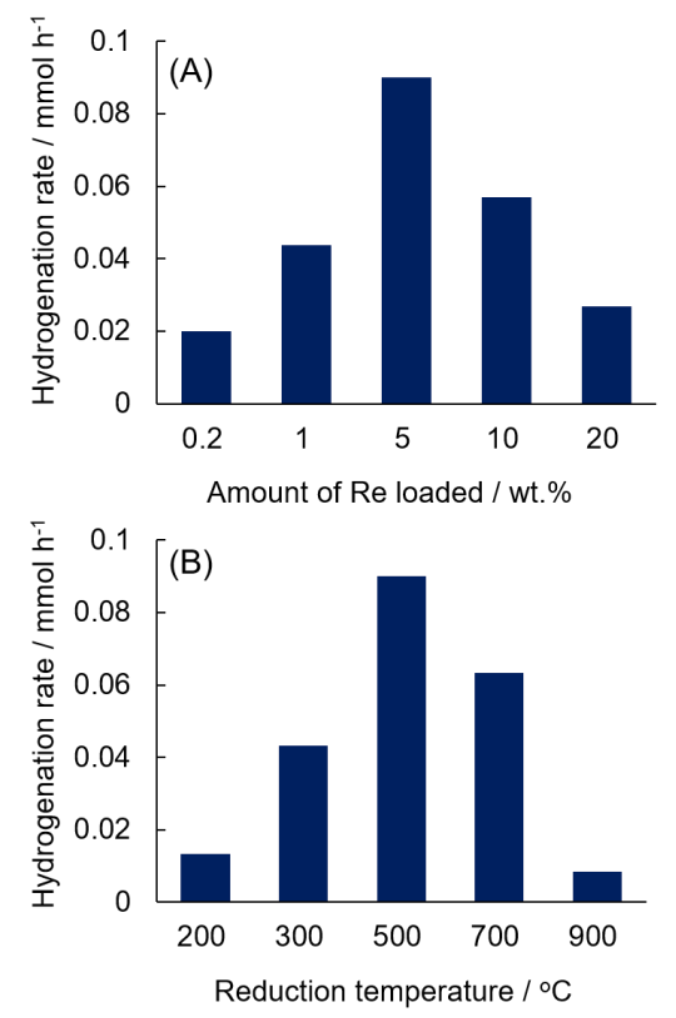

Figure 10. Effect of $(A)$ the Re loading and $(B)$ pretreatment reduction temperature on the hydrogenation of 3-phenylpropionic acid catalyzed by $\mathrm{Re}(\mathrm{x}) / \mathrm{TiO} \mathrm{O}_{2}\left(\mathrm{Re}(5) / \mathrm{TiO}_{2}\right.$ was used for the reduction temperature dependence). Hydrogenation rate $=$ the sum of the alcohol formation rate and one half the ester formation rate. Pre-treatment: $\mathrm{H}_{2}\left(30 \mathrm{~mL} \mathrm{~min}{ }^{-1}\right), 500{ }^{\circ} \mathrm{C}, 0.5 \mathrm{~h}$; reaction conditions: $2 \mathrm{~mol} \% \mathrm{Re}, 1 \mathrm{mmol} 3-$ phenylpropionic acid, no solvent, $5 \mathrm{MPa} \mathrm{H}_{2}, 140^{\circ} \mathrm{C}, 3 \mathrm{~h}$. 


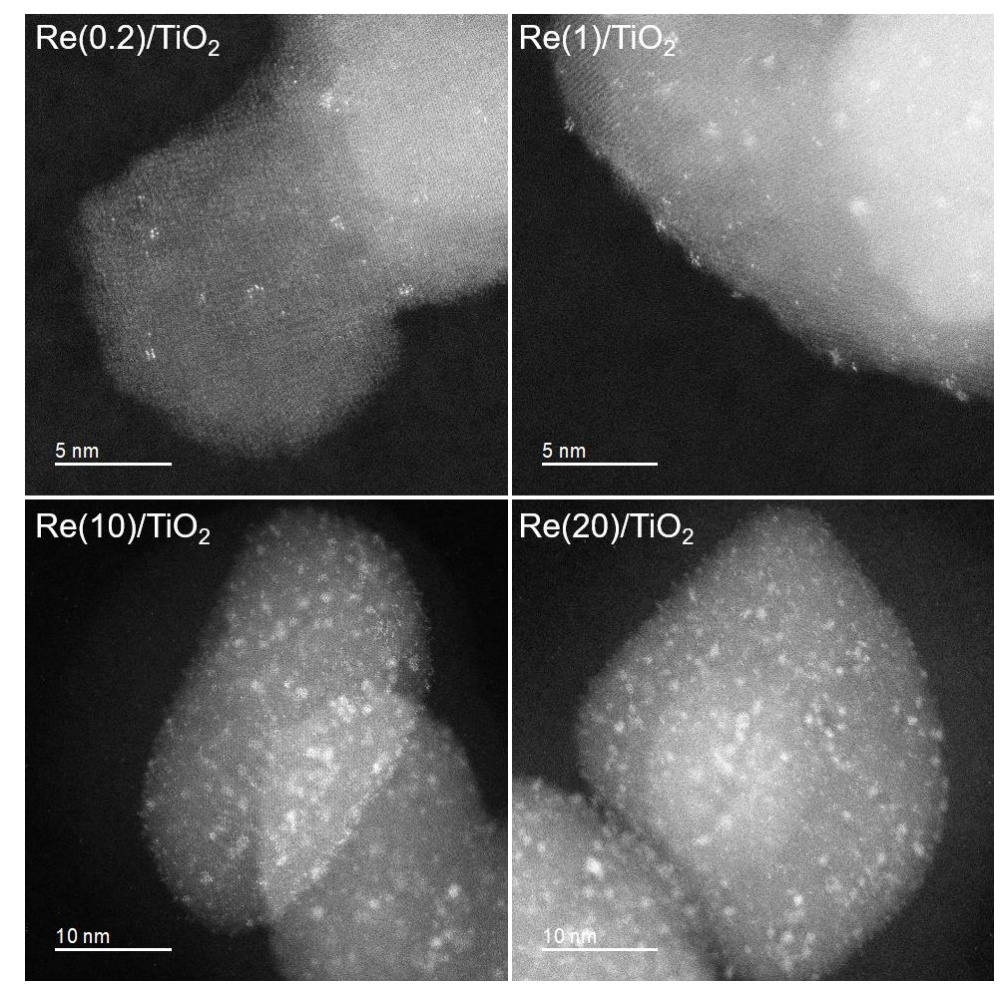

Figure 11. HAADF-STEM images for $\mathrm{Re}(\mathrm{x}) / \mathrm{TiO}_{2}(\mathrm{x}=0.2,1,10,20 \mathrm{wt} \%)$ reduced at $T=500{ }^{\circ} \mathrm{C}$ under a flow of $\mathrm{H}_{2}$. Due to the experimental setup, the samples were exposed to air before images were recorded.
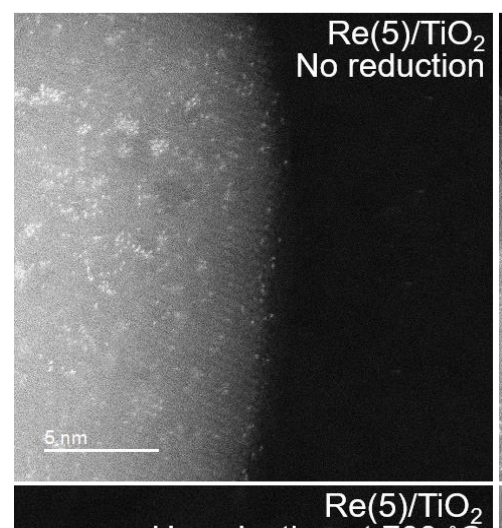
$\mathrm{H}_{2}$ reduction at $700{ }^{\circ} \mathrm{C}$
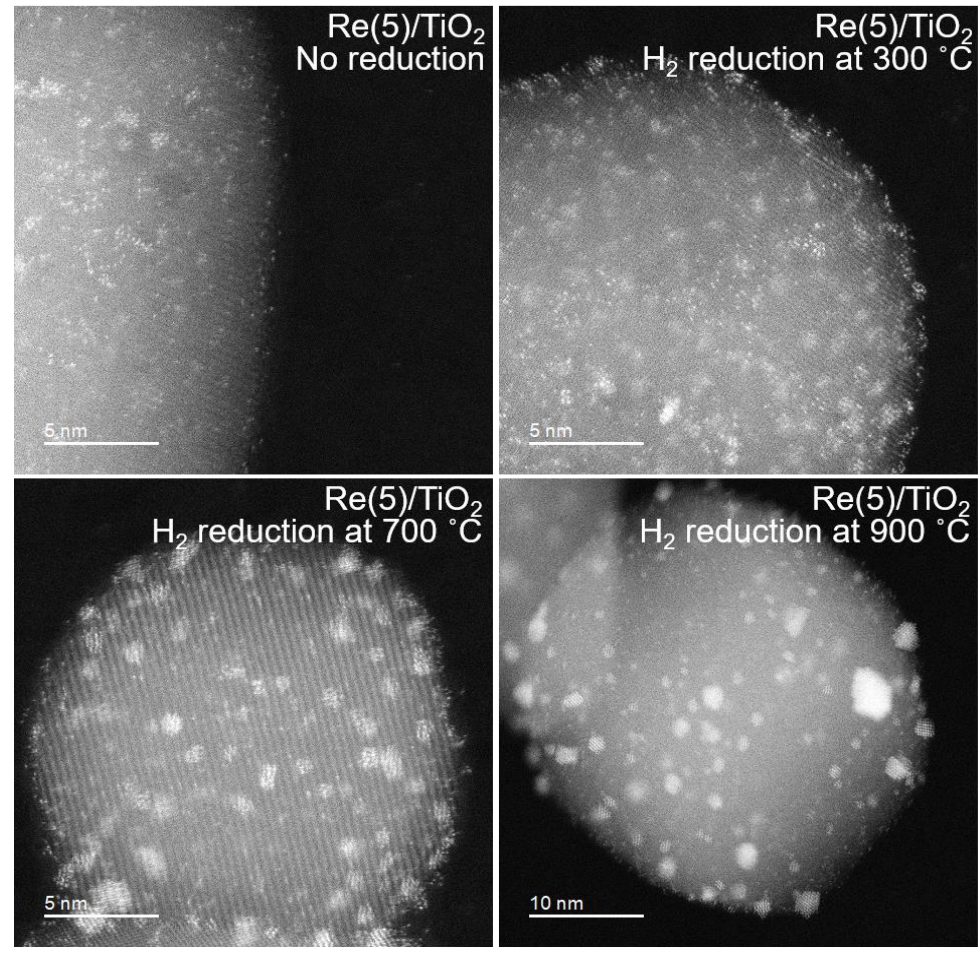

Figure 12. HAADF-STEM images for $\mathrm{Re}(5) / \mathrm{TiO}_{2}$ without reduction and reduced at $T=300,700$, and $900{ }^{\circ} \mathrm{C}$ under a flow of $\mathrm{H}_{2}$. Due to the experimental setup, the samples were exposed to air before images were recorded. 


\section{Selective hydrogenation of triglycerides}

Because it is highly desired to replace fossil fuels as chemical and energy sources, much attention has been given to the conversion of biomass materials into fuels and chemicals. ${ }^{66-72}$ Among biomass materials, triglycerides serve as the most important feedstocks for the synthesis of fatty amines, amides, nitriles and alcohols used in the production of surfactants, polymers and other useful commodity chemicals. ${ }^{73}$ However, benign manufacturing processes for the direct transformation of triglycerides into these chemicals are not well developed. In this study, we demonstrated the potential applicability of $\mathrm{Re}(5) / \mathrm{TiO}_{2}$ catalyzed hydrogenations to direct transformation of triglycerides into the corresponding alcohols. As shown in Table 3, hydrogenation reactions of a variety of triglycerides with different chain lengths (C4-C18), using $\mathrm{Re}(5) / \mathrm{TiO}_{2}$ pretreated with $5 \mathrm{MPa} \mathrm{H}_{2}$ at $500^{\circ} \mathrm{C}$, leads to formation of the corresponding alcohols without any solvents. 
Table 3. Catalytic hydrogenation of triglycerides to form alcohols using $\mathrm{Re}(5) / \mathrm{TiO}_{2}$. $^{\mathrm{a}}$

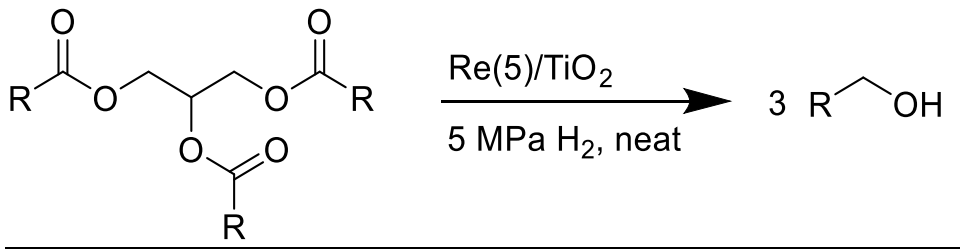

Entry Substrate $\quad$ Product $\quad$ Temperature $\left({ }^{\circ} \mathrm{C}\right)$ Time $(\mathrm{h})$ Alcohol yield $(\%)$

1

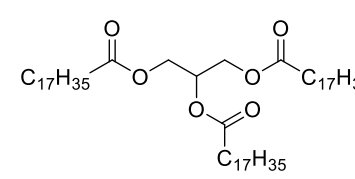

$\mathrm{C}_{17} \mathrm{H}_{35} \widehat{\mathrm{OH}} \quad 230$

30

$89(82)$

2

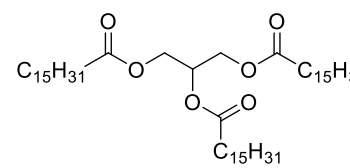

$\mathrm{C}_{15} \mathrm{H}_{31} \widehat{\mathrm{OH}} \quad 230$

30

$89(84)$

3

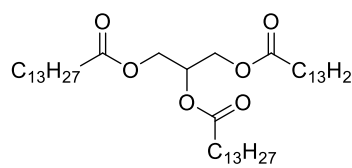

$\mathrm{C}_{13} \mathrm{H}_{27} \widehat{\mathrm{OH}} \quad 230$

$24 \quad 90(86)$

4

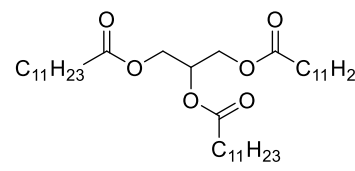

$\mathrm{C}_{11} \mathrm{H}_{23} \widehat{\mathrm{OH}} \quad 230$

30

$84(81)$

5

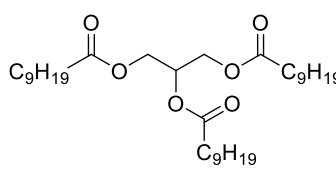

$\mathrm{C}_{9} \mathrm{H}_{19} \widehat{\mathrm{OH}} \quad 230$

24

$86(80)$

6<smiles>CCC(=O)OCC(COC(C)=O)OC(=O)OC</smiles>

$\mathrm{C}_{7} \mathrm{H}_{15} \widehat{\mathrm{OH}_{\mathrm{OH}}} \quad 230$

24

$66(62)$

7

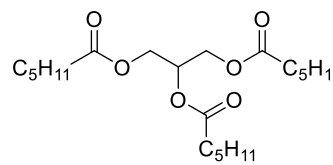

$\mathrm{C}_{5} \mathrm{H}_{11} \widehat{\mathrm{OH}} \quad 220$

36

$82(78)$

8

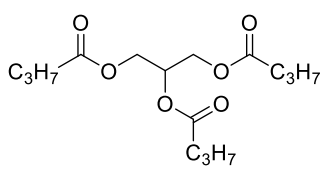
$\mathrm{C}_{3} \mathrm{H}_{7} \widehat{\widehat{O H}} \quad 220$ internal standard. Yields of isolated products are given in parenthesis. 


\section{Conclusions}

In the effort described above, we carried out a detailed mechanistic study of selective hydrogenation reactions of carboxylic acids and their derivatives promoted by $\mathrm{TiO}_{2}$-supported $\mathrm{Re}\left(\mathrm{Re} / \mathrm{TiO}_{2}\right)$ catalysts. The results show that the optimal Re loading and $\mathrm{H}_{2}$ pretreatment temperature are $5 \mathrm{wt} \%$ and $500{ }^{\circ} \mathrm{C}$, respectively. Detailed investigations using XRD, XAFS, and XPS as well as the STEM measurements were carried out to identify the catalytically active Re species. The results indicate that the active Re species should have sub-nanometer to a few nanometer sizes and average oxidation states higher than 0 and below +4 . Also, we found that $\mathrm{Re}$ on a $\mathrm{TiO}_{2}$ support is more highly dispersed than it is on the other supports such as $\mathrm{SiO}_{2}$, $\mathrm{Al}_{2} \mathrm{O}_{3}$, and Carbon. Furthermore, we observed that the $\mathrm{Re} / \mathrm{TiO}_{2}$ promotes hydrogenation of propylbenzene to form propylcyclohexane, indicating this catalytic system has the intrinsic ability to promote hydrogenation of aromatic rings. However, when either lauric acid or lauryl alcohol (or an amide or amine) is present in the reaction mixture, reductive dearomatization reactions do not take place. These observations suggest that strong adsorption of carboxylic acids and alcohols (or amides and amines) to the catalyst, caused by the oxophilic nature of Re, suppresses the dearomatization process. This finding is in accord with results of kinetic investigations, which showed that the order of the reaction with respect to the carboxylic acid is +0.03 . Finally, in a study aimed at demonstrating that the catalytic system can be used for conversion of biomass materials into value-added chemicals, we observed that $\mathrm{Re} / \mathrm{TiO}_{2}$ can be employed to convert triglycerides into the corresponding alcohols. 


\section{Conflicts of interest}

There are no conflicts to declare.

\section{Acknowledgements}

This work was financially supported by the JST-CREST project JPMJCR17J3, KAKENHI grants 17H01341, 18K14057, and 18K14051 from JSPS and by MEXT projects "Elements Strategy Initiative to Form Core Research Center" and IRCCS. The authors deeply thank the technical division of the Institute for Catalysis (Hokkaido University) for manufacturing experimental equipment and the technical staffs of Research Institute for Electronic Science, Hokkaido University for help with STEM observations. XAFS measurements were performed at the BL01B1 facility of SPring-8 at the JASRI (proposal No. 2018B1126). 


\section{Note and references}

1

A. M. Smith and R. Whyman, Chem. Rev., 2014, 114, 5477-5510.

J. Pritchard, G. A. Filonenko, R. van Putten, E. J. M. Hensen and E. A. Pidko, Chem. Soc. Rev., 2015, 44, 3808-3833.
K. Tomishige, Y. Nakagawa and M. Tamura, Green Chem., 2017, 19, 2876-2924.

T. Toyao, S. M. A. Hakim Siddiki, K. Kon and K. Shimizu, Chem. Rec., 2018, 18, 1374-1393.

J. Verduyckt, R. Coeck and D. E. De Vos, ACS Sustain. Chem. Eng., 2017, 5, 3290-3295.

P. A. Dub and T. Ikariya, ACS Catal., 2012, 2, 1718-1741.

D. S. Thakur and A. Kundu, J. Am. Oil Chem. Soc., 2016, 93, 1575-1593.

Y. Pouilloux, J. Catal., 1998, 176, 215-224.

H. Adkins and B. Wojcik, J. Am. Chem. Soc., 1934, 56, 2419-2424.

C. Hirosawa, N. Wakasa and T. Fuchikami, Tetrahedron Lett., 1996, 37, 6749-6752.

G. Beamson, A. J. Papworth, C. Philipps, A. M. Smith and R. Whyman, Adv. Synth. Catal., 2010, 352, 869-883.

M. Stein and B. Breit, Angew. Chemie - Int. Ed., 2013, 52, 2231-2234.

J. Coetzee, H. G. Manyar, C. Hardacre and D. J. Cole-Hamilton, ChemCatChem, 2013, 5, 2843-2847.

K. Shimizu, W. Onodera, A. S. Touchy, S. M. A. H. Siddiki, T. Toyao and K. Kon, ChemistrySelect, 2016,

\section{1, 736-740.}

R. A. Grey, G. P. Pez, A. Wallo and J. Corsi, J. Chem. Soc. Chem. Commun., 1980, 783-784.

Y. Hara, H. Inagaki, S. Nishimura and K. Wada, Chem. Lett., 1992, 21, 1983-1986.

X. Cui, Y. Li, C. Topf, K. Junge and M. Beller, Angew. Chemie - Int. Ed., 2015, 54, 10596-10599.

L. Deng, B. Kang, U. Englert, J. Klankermayer and R. Palkovits, ChemSusChem, 2016, 9, 177-180.

X. Fang, M. Sun, J. Zheng, B. Li, L. Ye, X. Wang, Z. Cao, H. Zhu and Y. Yuan, Sci. Rep., 2017, 7, 1-9.

S. Yoshioka and S. Saito, Chem. Commun., 2018, 54, 13319-13330.

H. T. Teunissen and C. J. Elsevier, Chem. Commun., 1998, 1367-1368.

K. Nomura, H. Ogura and Y. Imanishi, J. Mol. Catal. A Chem., 2001, 166, 345-349.

J. Zhang, G. Leitus, Y. Ben-David and D. Milstein, Angew. Chemie - Int. Ed., 2006, 45, 1113-1115.

W. Kuriyama, Y. Ino, O. Ogata, N. Sayo and T. Saito, Adv. Synth. Catal., 2010, 352, 92-96.

M. Ito, T. Ootsuka, R. Watari, A. Shiibashi, A. Himizu and T. Ikariya, J. Am. Chem. Soc., 2011, 133, 42404242.

T. vom Stein, M. Meuresch, D. Limper, M. Schmitz, M. Hölscher, J. Coetzee, D. J. Cole-Hamilton, J. Klankermayer and W. Leitner, J. Am. Chem. Soc., 2014, 136, 13217-13225.

M. Naruto and S. Saito, Nat. Commun., 2015, 6, 8140.

T. J. Korstanje, J. Ivar van der Vlugt, C. J. Elsevier and B. de Bruin, Science, 2015, 350, 298-302.

T. Toyao, S. M. A. H. Siddiki, A. S. Touchy, W. Onodera, K. Kon, Y. Morita, T. Kamachi, K. Yoshizawa and K. Shimizu, Chem. - A Eur. J., 2017, 23, 1001-1006. 
T. Toyao, S. M. A. H. Siddiki, Y. Morita, T. Kamachi, A. S. Touchy, W. Onodera, K. Kon, S. Furukawa, H. Ariga, K. Asakura, K. Yoshizawa and K. Shimizu, Chem. - A Eur. J., 2017, 23, 14848-14859. K. W. Ting, T. Toyao, S. M. A. H. Siddiki and K. I. Shimizu, ACS Catal., 2019, 9, 3685-3693.

N. D. Spencer and G. A. Somorjai, J. Catal., 1982, 72, 142-146.

L. Wang, R. Ohnishi and M. Ichikawa, J. Catal., 2000, 190, 276-283.

J. Ullrich and B. Breit, ACS Catal., 2018, 8, 785-789.

H. S. Lacheen, P. J. Cordeiro and E. Iglesia, Chem. - A Eur. J., 2007, 13, 3048-3057.

X. She, H. M. Brown, X. Zhang, B. K. Ahring and Y. Wang, ChemSusChem, 2011, 4, 1071-1073.

M. Chia, Y. J. Pagán-Torres, D. D. Hibbitts, Q. Tan, H. N. Pham, A. K. Datye, M. Neurock, R. J. Davis, J. A. Dumesic, Y. J. Pag, Y. J. Pagán-Torres, D. D. Hibbitts, Q. Tan, H. N. Pham, A. K. Datye, M. Neurock, R. J. Davis and J. A. Dumesic, J. Am. Chem. Soc., 2011, 133, 12675-12689.

S. Lwin, C. Keturakis, J. Handzlik, P. Sautet, Y. Li, A. I. Frenkel and I. E. Wachs, ACS Catal., 2015, 5, 1432-1444.

N. Ota, M. Tamura, Y. Nakagawa, K. Okumura and K. Tomishige, Angew. Chemie - Int. Ed., 2015, 54, $1897-1900$.

L. Sandbrink, E. Klindtworth, H. U. Islam, A. M. Beale and R. Palkovits, ACS Catal., 2016, 6, 677-680.

S. Tazawa, N. Ota, M. Tamura, Y. Nakagawa, K. Okumura and K. Tomishige, ACS Catal., 2016, 6, 6393-6397.

M. Tamura, N. Yuasa, J. Cao, Y. Nakagawa and K. Tomishige, Angew. Chemie - Int. Ed., 2018, 57, 8058 -8062 .

M. F. L. Johnson and V. M. LeRoy, J. Catal., 1974, 35, 434-440.

S. Tatarenko, P. Dolle, R. Morancho, M. Alnot, J. J. Ehrhardt and R. Ducros, Surf. Sci., 1983, 134, L505LS12.

45 F. Yang, D. Liu, H. Wang, X. Liu, J. Han, Q. Ge and X. Zhu, J. Catal., 2017, 349, 84-97.

46 S. R. Bare, F. D. Vila, M. E. Charochak, S. Prabhakar, W. J. Bradley, C. Jaye, D. A. Fischer, S. T. Hayashi, S. A. Bradley and J. J. Rehr, ACS Catal., 2017, 7, 1452-1461.

47 M. T. Greiner, T. C. R. Rocha, B. Johnson, A. Klyushin, A. Knop-Gericke and R. Schlögl, Zeitschrift fur Phys. Chemie, 2014, 228, 521-541.

48 H. Peled and M. Asscher, Surf. Sci., 1987, 183, 201-215.

49 A. S. Y. Chan, W. Chen, H. Wang, J. E. Rowe and T. E. Madey, J. Phys. Chem. B, 2004, 108, 1464314651.

50 S. R. Bare, S. D. Kelly, F. D.vila, E. Boldingh, E. Karapetrova, J. Kas, G. E. Mickelson, F. S. Modica, N. Yang and J. J. Rehr, J. Phys. Chem. C, 2011, 115, 5740-5755.

51 S. Koso, H. Watanabe, K. Okumura, Y. Nakagawa and K. Tomishige, J. Phys. Chem. C, 2012, 116, 3079-3090.

53 Y. Takeda, M. Tamura, Y. Nakagawa, K. Okumura and K. Tomishige, ACS Catal., 2015, 5, 7034-7047. 
S. Lwin, Y. Li, A. I. Frenkel and I. E. Wachs, ACS Catal., 2015, 5, 6807-6814.

N. Ota, M. Tamura, Y. Nakagawa, K. Okumura and K. Tomishige, ACS Catal., 2016, 6, 3213-3226.

B. Mitra, X. Gao, I. E. Wachs, A. M. Hirt and G. Deo, Phys. Chem. Chem. Phys., 2001, 3, 1144-1152.

J. Okal, Appl. Catal. A Gen., 2005, 287, 214-220.

X. She, J. H. Kwak, J. Sun, J. Hu, M. Y. Hu, C. Wang, C. H. F. Peden and Y. Wang, ACS Catal., 2012, 2 , 1020-1026.

60 D. D. Falcone, J. H. Hack, A. Y. Klyushin, A. Knop-Gericke, R. Schlögl and R. J. Davis, ACS Catal., 2015, 5, 5679-5695.

B. K. Ly, B. Tapin, M. Aouine, P. Delichere, F. Epron, C. Pinel, C. Especel and M. Besson, ChemCatChem, 2015, 7, 2161-2178.

62 K. Liu, J. Pritchard, L. Lu, R. Van Putten, M. W. G. M. Verhoeven, M. Schmitkamp, X. Huang, L. Lefort, C. J. Kiely, E. J. M. Hensen and E. A. Pidko, Chem. Commun., 2017, 53, 9761-9764.

S. T. Thompson and H. H. Lamb, J. Catal., 2017, 350, 111-121. Y. Nakagawa, S. Tazawa, T. Wang, M. Tamura, N. Hiyoshi, K. Okumura and K. Tomishige, ACS Catal., 2018, 8, 584-595.

B. Peng, Y. Yao, C. Zhao and J. A. Lercher, Angew. Chemie - Int. Ed., 2012, 51, 2072-2075.

R. Beerthuis, G. Rothenberg and N. R. Shiju, Green Chem., 2015, 17, 1341-1361. Chem., 2015, 24, 646-654.

B. Rozmysłowicz, A. Kirilin, A. Aho, H. Manyar, C. Hardacre, J. Wärnå, T. Salmi and D. Y. Murzin, J. Catal., 2015, 328, 197-207.

A. M. Robinson, J. E. Hensley and J. Will Medlin, ACS Catal., 2016, 6, 5026-5043. Z. Maeno and K. Shimizu, ChemSusChem, 2019, 12, 3115-3125. 